\title{
SISTEMA SETORIAL DE INOVAÇÃO NO AGRONEGÓCIO: UMA ANÁLISE PARAA PRODUÇÃO DE AZEITE DE OLIVA NO RS ${ }^{\circ *}$
}

\author{
SECTORIAL SYSTEM OF INNOVATION IN AGRIBUSINESS: AN \\ ANALYSIS FOR THE PRODUCTION OF OLIVE OIL IN RS
}

\author{
Aline Caye ** $^{*}$ \\ Janaina Ruffoni** \\ Denise Dumoncel Righetto Ziegler**
}

enviado: 2 octubre 2018 - aceptado: 07 agosto 2019

\begin{abstract}
Resumo
A temática abordada neste trabalho refere-se ao Sistema Setorial de Inovação (SSI) de Azeite de Oliva no Rio Grande do Sul (RS). Faz-se uso de uma perspectiva sistêmica para analisar o desenvolvimento de um setor produtor de um bem de valor agregado do agronegócio do RS. O objetivo é compreender elementos e atores que explicam o desenvolvimento desse SSI. Trata-se de uma pesquisa exploratória, tendo sido realizadas pesquisas bibliográfica, documental e de campo, ao longo do ano de 2017. Os principais resultados apontam que esse SSI constituiu-se com mais vigor recentemente e está em processo de consolidação.

Palavras-chave: sistema setorial de inovação, agronegócio, azeite de oliva, Rio Grande do Sul/Brasil.

Código JEL: Q16, O30.

\footnotetext{
<?> * Este trabalho integra os esforços realizados no âmbito do projeto de pesquisa "Caminhos da Inovação do Agronegócio Gaúcho” coordenado pelo NITEC/UFRGS. O Grupo de Estudos em Dinâmica Econômica da Inovação (GDIN) da Universidade do Vale do Rio dos Sinos (UNISINOS) é parceiro neste projeto. A pesquisa é financiada pelo Conselho Nacional de Desenvolvimento Científico e Tecnológico (CNPq) e pela Fundação de Amparo à Pesquisa do Rio Grande do Sul (FAPERGS). Para maiores detalhes http://nitec.co/caminhosdainovacaodoagronegociogaucho/. O artigo apresentado é uma síntese do trabalho de dissertação de mestrado de Caye (2018).

<?> Caye, A., Ruffoni, J., \& Righetto Ziegler, D. D. (2020). Sectorial system of innovation in agribusiness: an analysis for the production of olive oil in RS. Estudios económicos, 37 (75), 75-105.

<?> Universidade do Vale do Rio dos Sinos, UNISINOS/RS, Brasil. E-mail: linecaye@gmail.com, jruffoni@unisinos.br, deniseziegler@outlook.com.br
} 


\begin{abstract}
The thematic addressed in this paper refers to the Sectorial System of Innovation (SSI) of olive oil production activity in Rio Grande do Sul (RS). It was applied a systemic analysis to understand the development of a sector that produce a valueadded product in RS agribusiness, The methodological procedures were characterized as exploratory and descriptive, having been carried out bibliographical, documentary and field researches, throughout 2017. The main results indicate that this SSI has been more vigorous recently and is still in the process of consolidation.

Keywords: sectorial system of innovation, agribusiness, olive oil, Rio Grande do Sul/Brazil.

JEL Code: Q16, O30.
\end{abstract}




\section{INTRODUÇÃO}

O tema deste trabalho é o Sistema Setorial de Inovação de azeite de oliva no Rio Grande do Sul (RS). Uma das discussões atuais a respeito do agronegócio brasileiro, e também do gaúcho, é a necessidade de serem realizadas atividades produtivas de maior valor agregado, diferenciando dos tradicionais produtos do agronegócio, as commodities. Neste sentido, considerou-se relevante estudar uma atividade de alto valor agregado do agronegócio do RS. O objetivo central deste trabalho é compreender quais são e como se comportam os elementos e atores que explicam o desenvolvimento da produção de azeite de oliva no RS.

Atualmente, quase a totalidade do azeite de oliva consumido no país é importada. O Ministério da Agricultura, Pecuária e Abastecimento - MAPA(2017) divulgou que, conforme dados do COI (Conselho Oleícola Internacional), o Brasil é o terceiro maior importador de azeite de oliva do mundo, o que correspondeu à importação de cerca de 50 milhões de toneladas do produto em 2016. "Aproximadamente 10 milhões de hectares são cultivados com oliveiras em todo o mundo, sendo que 90\% da área concentra-se na costa do Mar Mediterrâneo" (Coutinho et al., 2015, p. 14). Os autores mencionam que, no ano de 2014, de acordo com dados divulgados do COI, os principais países produtores de azeite de oliva foram, respectivamente, Espanha, Itália, Grécia, Síria, Turquia, Tunísia, Marrocos, Portugal e Argélia. Os autores complementam que há potencial para o Brasil se tornar um grande produtor de azeitonas no médio e longo prazos. Porém, para que isso ocorra, é necessário disponibilizar acesso às informações técnicas para aqueles que pretendem investir nessa cultura agrícola, pois a maioria dos negócios em olivicultura ainda ocorre sem a utilização de tecnologia adequada.

A produção de azeite de oliva no RS é retomada recentemente a partir de 2003 com o cultivo de mudas de oliva em Caçapava do Sul/RS, conforme a Empresa de Assistência Técnica e Extensão Rural do RS - EMATER/RS-Ascar (2015). Desde então, a plantação de olivais vem crescendo no estado, bem como a instalação de fábricas de azeites de oliva. Coutinho et al. (2015) mencionam que o cultivo de oliveiras é favorecido no RS pelo clima propício para a cultura, preço da terra atrativo e topografia plana - da metade sul do Estado - ser propícia para mecanização, o que aumenta a possibilidade de expansão. Além disso, esse cultivo é uma atividade de baixo impacto ambiental, o que a torna ainda mais atrativa. Em termos de demanda, a produção deste tipo de azeite, conforme Xiong, Sumner, e Matthews (2014), vem aumentando devido à atual valorização da saúde alimentar, dos benefícios culinários do produto e da disseminação da dieta do Mediterrâneo. 
Entende-se que a importância deste estudo também reside em compreender as práticas adotadas pela agroindústria gaúcha para produzir e inovar na oferta de um produto de elevado valor agregado. Em termos teóricos, a justificativa da pesquisa reside em aplicar um olhar sistêmico a esse processo. Para tanto, utiliza-se como recorte teórico a abordagem de Sistema Setorial de Inovação (SSI), a qual permite a compreensão de elementos que vão além da firma e sua estrutura de mercado para compreender a dinâmica produtiva e inovativa. Segundo Malerba (2002), a abordagem de Sistema Setorial de Inovação (SSI) fornece uma visão multidimensional, integrada e dinâmica. É caracterizada por um conjunto de produtos e agentes que realizam interações comerciais e não comerciais, para a criação, produção e venda desses produtos. O autor também menciona que um SSI possui uma base de conhecimento específica, tecnologias, insumos e demanda existente, emergencial e potencial.

Sendo assim, o problema de pesquisa do estudo é: quais são e como se comportam os elementos e atores que explicam o desenvolvimento do Sistema Setorial de Inovação de azeite de oliva no Rio Grande do Sul?

Para tanto, além desta Introdução, este artigo apresenta mais seis seções. Na segunda foi realizada uma revisão bibliográfica a respeito de Sistema Setorial de Inovação. A terceira aborda o negócio de azeite de oliva no RS. Na quarta seção está a metodologia utilizada. Na seção cinco são apresentados os resultados relativos à origem do azeite de oliva e sua valorização econômica; tecnologia, constituição dos negócios e firmas do setor; mercado; instituições/organizações; e processo de geração e difusão do conhecimento/inovações. A seção seis apresenta a discussão dos resultados. E, por fim, são feitas as considerações finais.

\section{FUNDAMENTAÇÃO TEÓRICA}

Conforme Freeman (1987) e Nelson (1993) apud Edquist (2006), o Sistema Nacional de Inovação (SNI) aborda o limite geográfico nacional do sistema de inovação dado e analisa o funcionamento do conjunto de atores envolvidos nos processos de inovação e difusão, bem como as relações entre eles. Lundvall (1993) complementa que no SNI busca-se identificar atores que compartilham uma cultura, história, linguagem, instituições sociais e políticas comuns, enfatizando, assim, o papel da nação. Já, conforme Edquist (2006), no Sistema Regional de Inovação (SRI) os limites se referem a uma região ou área específica, com características históricas, sociais, culturais ou produtivas bem definidas. 
Para Edquist (2006), o SNI e o SRI não se concentram em indústrias ou em tecnologias específicas. Os sistemas nacionais e regionais se concentram em todo o conjunto de indústrias atuantes em um país ou região específica e nas instituições que os apoiam. De acordo com Schrempf et al. (2013), o SNI e o SRI abordam a delimitação geográfica para caracterizar os sistemas, enquanto que a abordagem do Sistema Setorial de Inovação (SSI) concentra-se em certos setores da economia. Edquist (2006) também argumenta que o SSI é composto por empresas, principalmente privadas, que atuam nas atividades inovadoras de um setor, através do desenvolvimento e da fabricação de produtos e da geração e utilização de tecnologias. Essas empresas estão relacionadas de duas maneiras diferentes: através de processos de interação e cooperação no desenvolvimento de tecnologia e através de processos de competição e seleção em atividades inovadoras e de mercado.

De acordo com Malerba (2002), as vantagens de uma visão setorial do sistema envolvem a melhor compreensão da estrutura e dos limites de um setor, dos agentes e das suas interações, dos processos de aprendizagem, inovação e produção, da transformação de setores e os fatores na base do desempenho diferencial de empresas e países em um setor. Malerba (2003) descreve que uma estrutura de sistema setorial pode permitir análises detalhadas da inovação nos setores, em termos de processos de conhecimento e aprendizagem, estrutura e instituições. Para Dosi (1982), enfatizar o papel desempenhado pelos fatores específicos do setor e da tecnologia possui antecedentes nas noções de trajetórias e paradigmas tecnológicos. Segundo Malerba (2003), uma abordagem de sistema setorial fornece uma maneira de examinar a dinâmica dos setores de acordo com a inovação e as mudanças tecnológicas, e os processos coevolucionários que ocorrem entre conhecimento, tecnologia, atores e instituições.

Conforme Malerba (2002), há quatro elementos que caracterizam um Sistema Setorial de Inovação: firmas e constituição dos negócios; mercado; instituições e organizações e processo de geração e difusão do conhecimento/inovações. Para o autor, o SSI é formado por um conjunto de produtos e por um conjunto de agentes que realizam interações comerciais e não comerciais, para a criação, produção e venda desses produtos. Para o autor, o SSI fornece uma visão multidimensional, integrada e dinâmica dos setores, além de possuir uma base de conhecimento específica, tecnologias, insumos e demanda existente, emergencial e potencial. $\mathrm{O}$ autor também aborda que os agentes que compõem o sistema setorial são indivíduos e organizações, em vários níveis de agregação, e possuem processos de aprendizagem específicos, competências, estruturas organizacionais, crenças, objetivos e comportamentos. Esses agentes interagem, moldados por instituições, através de processos de comunicação, intercâmbio, cooperação, competição e comando. Já 
para Edquist (2006), os atores centrais do SSI são empresas privadas. Sendo assim, a dinâmica das empresas que atuam em um setor é uma preocupação central da abordagem de SSI.

Conforme Edquist (2006), o conceito de SSI concentra-se em relações competitivas entre as empresas, considerando o papel do ambiente de seleção. Lembrando que os processos de concorrência e seleção envolvem empresas com diferentes capacidades e performances inovadoras. Lee e Malerba (2017) descrevem que mudanças sucessivas na liderança do setor, também chamadas de ciclo de catch-up, ocorrem ao longo do tempo, a exemplo de muitas indústrias que testemunharam mudanças na liderança do setor. Nesses ciclos, o líder tradicional do setor não consegue manter sua superioridade em tecnologia, produção e marketing e, com isso, novas empresas e países se firmam nessa posição. Mais tarde, o emergente que conquistou essa liderança vai deixar sua posição para um novo emergente, caracterizando uma dinâmica de mercado.

Para Malerba (2002), os sistemas setoriais podem diferir muito em relação às suas instituições, que podem surgir como resultado de uma decisão planejada por empresas ou outras organizações, ou podem surgir como consequência imprevista da interação dos agentes. $\mathrm{O}$ autor menciona que a mesma instituição pode ter características diferentes em diferentes países e, portanto, pode afetar o mesmo sistema setorial de forma diferente. Alguns sistemas setoriais podem se tornar predominantes em um país porque as instituições existentes nesse país fornecem um ambiente mais apropriado para certos tipos de setores e não para outros. Malerba (2003) afirma que a inovação difere entre os setores em termos de fontes de inovação, fronteiras, atores e características do processo de inovação, organização de atividades inovadoras, instituições relevantes e seus efeitos no crescimento e desempenho setorial. Edquist (2006) complementa que, embora os atores centrais do SSI sejam as empresas privadas, não se deve negligenciar o papel desempenhado por outros agentes e organizações em influenciar atividades inovadoras e no estabelecimento de regras de concorrência.

Segundo Freeman (1995), a geração de conhecimento, sua transformação e apropriação, acontece a partir das interações entre diversas instituições que, dependendo da intensidade, produzem impactos muito além da geração de novos produtos e processos, e são determinantes para o próprio sucesso. Para o autor, a inovação ocorre a partir de múltiplos processos de aprendizados. Negri e Squeff (2016) acrescentam que as infraestruturas de pesquisa constituem a base de um SSI. Nesse sentido, o Brasil experimentou nas últimas décadas um contínuo e intenso crescimento de sua participação relativa no número de artigos publicados 
em periódicos indexados internacionalmente. Porém, na área da agricultura, a concentração das publicações é menor, considerando como referência o United States Department of Agriculture (USDA).

\section{O NEGÓCIO DE AZEITE DE OLIVA NO RS}

Conforme Santos (2002), a história do cultivo da oliveira ${ }^{1}$ se confunde com a história da agricultura na região mediterrânea. Oliveira (2012) menciona que a origem da oliveira, frequentemente, é atribuída à Síria ou ao Líbano (Ásia Menor Meridional), pois, nesta região, a origem da oliveira data da época neolítica (cerca de 8000 anos antes da Era Cristã).

Santos (2002) relata que no século XVI a colonização espanhola trouxe as oliveiras para a América, através de missioneiros e emigrantes. Oliveira (2012) complementa que a oliveira foi introduzida no Brasil pelos portugueses, por volta de 1800. E Coutinho et al. (2015) descrevem que, na atualidade, as oliveiras também são cultivadas em países como África do Sul, China, Nova Zelândia, Uruguai, Austrália, Marrocos, entre outros.

Conforme Coutinho et al. (2015), a oliveira foi introduzida oficialmente no RS, em 1948, através da criação do Serviço Oleícola, pela Secretaria da Agricultura do Estado, que permaneceu até o início dos anos de 1960. Oliveira (2012) expõe que a oliveira não obteve destaque econômico em solo brasileiro, o que pode estar relacionado à adaptação, falta de tecnologia e forte política de importação do produto final implementada no país. Em 2003, foi retomado o cultivo de mudas de oliveira, em Caçapava do Sul/RS, conforme a EMATER/RS-Ascar (2015), e, desde então, vem sendo considerado um exemplo de agregação de valor e inovação para o agronegócio do Rio Grande do Sul. De acordo com Oliveira (2012), a oliveira vem sendo pesquisada com um enfoque mais científico que no passado, revelando seus princípios ativos e composição química, como no caso dos efeitos antioxidantes das folhas da oliveira.

Segundo Wrege et al. (2015), ao redor dos paralelos $30^{\circ} \mathrm{N}$ e $30^{\circ} \mathrm{S}$ são os principais pontos de ocorrência de oliveiras. Já no Brasil, o clima ideal para matu-

1 A oliveira, segundo Albin e Vilamil (2003), cujo nome científico é Olea europaea L., produz o fruto oliva, também chamado de azeitona, do qual é extraído um suco oleoso e denso, de coloração dourada esverdeada, chamado azeite de oliva. Segundo os autores, a palavra azeite deriva do nome árabe "az-zait”, que significa suco de oliva. 
ração dos frutos da oliveira, de acordo com Wrege et al. (2012), é encontrado na metade sul do estado do Rio Grande do Sul, cuja temperatura se encontra entre 25 e 35 graus centígrados, dentro da faixa de temperatura ideal para a maturação dos frutos. E, no inverno, são comuns temperaturas entre 3 e 15 graus centígrados.

Coutinho et al. (2015) descrevem o zoneamento edafoclimático para a cultura da oliveira no RS, de acordo com a Figura 1. Como pode ser observado, o RS não tem áreas preferenciais para o cultivo de oliveiras, mas tem áreas recomendáveis e pouco recomendáveis. Coutinho et al. (2015) descrevem que as áreas altas da região nordeste apresentam geadas e ventos, e as áreas baixas, próximas aos principais corpos de água doce, são úmidas e apresentam problemas de drenagem do solo. Além disso, na região sul, há pedregosidade ou rochosidade em abundância, o que dificulta o desenvolvimento da oliveira.

Conforme Oliveira (2012), a produtividade da oliveira depende de alguns fatores relacionados ao solo, às características genéticas e às condições ambientais, como o clima, que, quando adequados, propiciam à planta capacidade máxima de crescimento e de produção. Nesse sentido, a correção e a adubação do solo devem ser realizadas para manter a disponibilidade de nutrientes para a planta. Percussi (2011) complementa apontando que, desde a antiguidade, os olivais sofrem com os ataques de várias pragas, como insetos, fungos, ervas daninhas, parasitas e bactérias que provocam doenças nas plantas. Oliveira (2012) defende que o uso da terra de acordo com a sua capacidade, a manutenção da cobertura do solo, a adubação verde, o uso de matéria orgânica, o uso racional de corretivos, de fertilizantes, de agrotóxicos e o manejo integrado de pragas e doenças são formas de obter uma produção sustentável.

De acordo com Coutinho et al. (2015), a implantação e a condução do olival dependem, entre outros aspectos, do conhecimento de seus custos, identificando os itens que mais oneram a produção. Para a implantação do olival, são necessários investimentos iniciais, como a área de terra e seu preparo, mudas², insumos,

2 A qualidade da muda é de extrema importância para o êxito do olival. De acordo com o Cadastro Olivícola 2017, divulgado pela SEAPDR/RS (2018), as variedades de oliveiras mais cultivadas no RS são, respectivamente, Arbequina (espanhola), Koroneiki (grega), Picual (espanhola), Arbosana (espanhola), Frantoio (italiana), Manzanilla (espanhola) e Coratina (italiana). Marques (2017) menciona que a variedade Grappolo, de origem italiana, é uma das principais variedades cultivadas no Brasil. O autor também relata que existe um cultivar brasileiro, chamado Maria da Fé, e que no mundo existem duas mil (2000) espécies de azeitonas cultivadas. Oliveira (2012) acrescenta que o cultivo comercial de mudas de oliveiras é recente no Brasil e está em expansão, estimando-se um mercado potencial de cerca de 11 milhões de mudas. 
equipamentos, infraestrutura e mão de obra. Os autores constataram que o custo de manutenção, nos três (3) primeiros anos, é maior do que o de implantação, devido aos custos com calagens, colheita e maior utilização de maquinários e mão de obra, e que, quando não previstos, podem inviabilizar o empreendimento.

Conforme o MAPA (2017), o azeite de oliva virgem pode ser classificado de acordo com os seguintes tipos: 1 ) extra virgem (acidez menor que $0.8 \%$ ); 2 ) virgem (acidez entre $0.8 \%$ e $2 \%$ ); e 3 ) lampante (acidez maior que $2 \%$ ). Segundo o órgão, os dois primeiros tipos de azeite de oliva virgem podem ser consumidos in natura, mantendo todos os aspectos benéficos ao organismo. O terceiro tipo, lampante, somente pode ser consumido após ser refinado, passando então a ser classificado como azeite de oliva refinado.

Figura 1. Zoneamento Edafoclimático - Cultura da Oliveira no RS

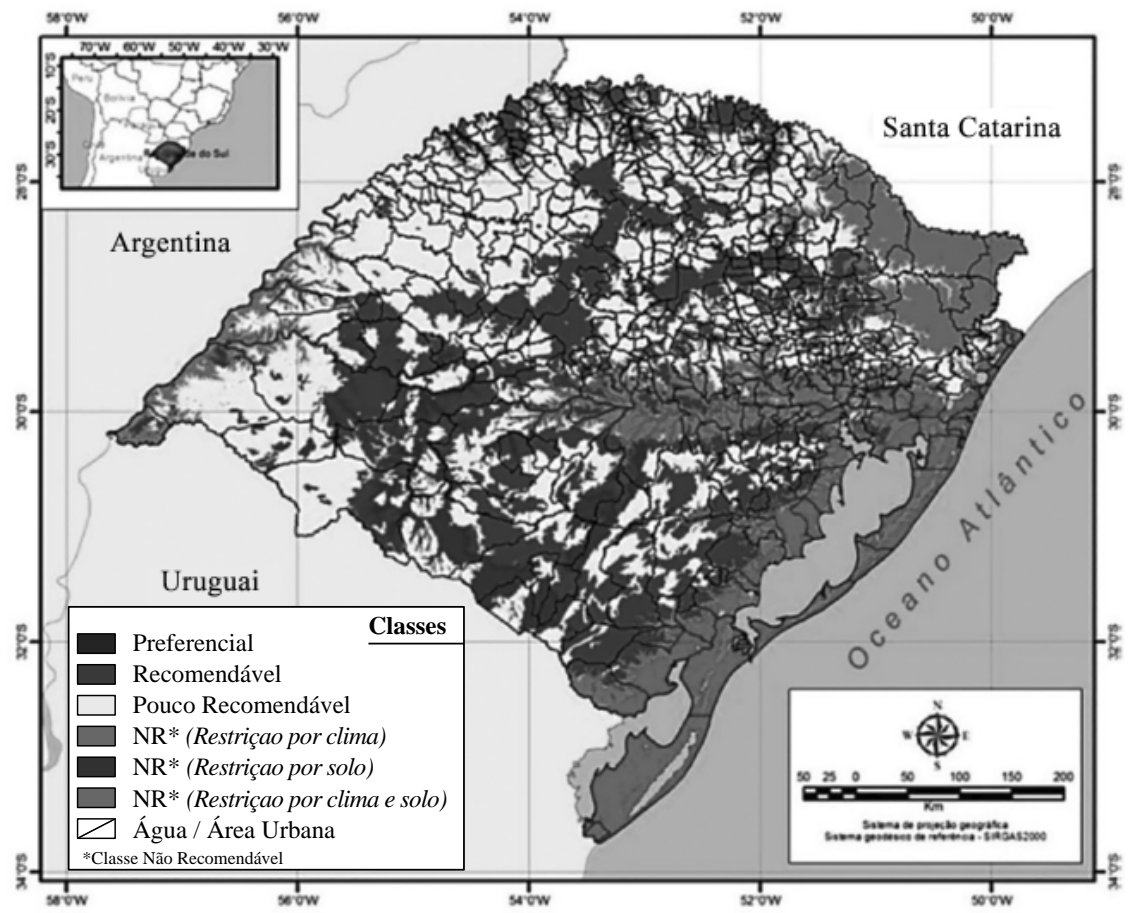

Fonte: Filippini Alba et al. (2013) apud Coutinho et al. (2015, p. 50). 
Marques (2017) relata que, além do cuidado com o olival, alguns fatores influenciam na qualidade, no aroma e no sabor do azeite de oliva, tais como: a espécie de oliveira cultivada; o clima do local do cultivo; o estágio de maturação da azeitona no momento da colheita; a técnica de extração do azeite, que pode variar desde os moinhos de pedra mais antigos até os modernos lagares. $\mathrm{O}$ autor menciona que para o azeite de oliva ser considerado extra virgem, precisa atender a parâmetros químicos, atestados em laboratório, e sensoriais, analisados por painéis sensoriais de especialistas, que classificam o frutado, o amargor e a picância do azeite de oliva, em escala de zero (0) a dez (10) de intensidade, o que indicará se o azeite é suave, médio ou intenso. O azeite de oliva é considerado equilibrado quando esses três parâmetros estiverem alinhados, o que favorece a performance sensorial do azeite de oliva extra virgem como condimento.

Marques (2017) acrescenta que o azeite deve ter acidez inferior a 0.8\%, aromas frescos e não apresentar defeitos, que podem surgir na fase da colheita, da produção e no armazenamento. $\mathrm{O}$ autor acrescenta que, embora existam centenas de olivicultores no Brasil, apenas alguns tem produção estável e regular, em escala comercial. Mas garante que, de uma forma geral, os azeites brasileiros são frescos, jovens e de excelente qualidade.

\section{PROCEDIMENTOS METODOLÓGICOS}

Trata-se de uma pesquisa exploratória, cujas pesquisas bibliográfica, documental e de campo foram realizadas para a identificação dos elementos e atores que explicam o desenvolvimento do Sistema Setorial de Inovação de azeite de oliva no Rio Grande do Sul. Na pesquisa de campo, foi aplicado roteiro semiestruturado de questões com 21 atores, que integram esse SSI, entre os meses de julho e dezembro de 2017.

Quanto às entrevistas, foram pesquisadas firmas e instituições. O tipo de amostragem utilizada foi "não probabilística”. Foi utilizada a documentação direta através da pesquisa de campo, que se constitui no levantamento de dados no local em que os fenômenos ocorrem, e realizada por meio das técnicas de observação assimétrica (espontânea e informal) e de entrevista semiestruturada. Também foi utilizada a observação participante, conhecida como observação ativa, que "consiste na participação real do conhecimento na vida da comunidade, do grupo ou de uma situação determinada” (Gil, 2011, p. 103). 
Os 21 entrevistados foram escolhidos por serem atores atuantes no setor de azeite de oliva; alguns foram identificados previamente, pela pesquisa documental realizada, e outros foram indicados seguindo o critério de importância para o SSI. O tempo médio foi de quarenta e cinco (45) minutos para cada entrevista, sendo realizadas com: seis (6) produtores das cinco (5) maiores empresas de azeite extra virgem do estado do RS; um (1) pequeno produtor; um (1) produtor que está trazendo a sua produção do Chile; os três (3) viveiristas de mudas de oliveiras do RS, cadastrados junto ao Pró-Oliva, sendo que esses viveiristas também são produtores; um (1) azeitólogo; uma (1) comerciante de loja especializada de azeite de oliva; dois (2) pesquisadores vinculados a duas (2) universidades e a um (1) instituto tecnológico; um (1) instituto brasileiro; três (3) pesquisadores vinculados a órgãos governamentais; dois (2) representantes do governo, um deles federal e o outro estadual. Outras tentativas de entrevistas foram feitas: duas associações de produtores de azeite de oliva do RS e uma grande varejista. Entretanto, esses atores optaram por não participar da pesquisa ${ }^{3}$.

A pesquisa bibliográfica foi realizada, principalmente, com base em artigos científicos publicados a respeito de inovação, Sistema Setorial de Inovação, inovação no setor agroalimentar e azeite de oliva. Já a pesquisa documental foi realizada através de material disponibilizado em sites de consulta de instituições diversas, como COI, EMBRAPA, EMATER/RS-Ascar e Secretaria da Agricultura, Pecuária e Desenvolvimento Rural do RS (SEAPDR/RS). No Quadro 1 está a lista dos 21 entrevistados e suas codificações.

Quadro 1. Informações referentes aos entrevistados na pesquisa de campo

\begin{tabular}{llllll}
\hline Código & Entrevistado & Empresa & Localização & $\begin{array}{l}\text { Data da } \\
\text { Entrevista }\end{array}$ & $\begin{array}{l}\text { Tempo de } \\
\text { Duração da } \\
\text { Entrevista }\end{array}$ \\
\hline P1E1 & Produtor 1 & Empresa 1 & Pinheiro Machado/RS & 08/09/2017 & 54 min e 07 seg \\
\hline P2E2 & Produtor 2 & Empresa 2 & Caçapava do Sul/RS & $05 / 10 / 2017$ & $\begin{array}{l}1 \mathrm{~h}, 10 \mathrm{~min} \text { e } \\
58 \text { seg }\end{array}$ \\
\hline P3E2 & Produtor 3 & Empresa 2 & Caçapava do Sul/RS & $05 / 10 / 2017$ & $\begin{array}{l}1 \mathrm{~h}, 10 \text { min e } \\
58 \text { seg }\end{array}$ \\
\hline P4E3 & Produtor 4 & Empresa 3 & Canguçu/RS & $04 / 09 / 2017$ & 42 min e 13 seg \\
\hline
\end{tabular}

3 Rodrigues (2016), também relatou que tinha a intenção de entrevistar uma das duas associações de olivicultores do RS, porém não obteve sucesso. Além disso, o autor mencionou que os seus entrevistados também consideraram estas associações de pouca relevância para o setor. 


\begin{tabular}{|c|c|c|c|c|c|}
\hline P5E4 & Produtor 5 & Empresa 4 & Cachoeira do Sul/RS & 06/09/2017 & $44 \mathrm{~min}$ e $53 \mathrm{seg}$ \\
\hline P6E5 & Produtor 6 & Empresa 5 & $\begin{array}{l}\text { Sant'Ana do } \\
\text { Livramento/RS }\end{array}$ & $18 / 10 / 2017$ & 46 min e 49 seg \\
\hline P7E6 & Produtor 7 & Empresa 6 & Caçapava do Sul/RS & 03/10/2017 & $1 \mathrm{~h}$ e 2 seg \\
\hline P8E7 & Produtor 8 & Empresa 7 & Vacaria/RS & $23 / 10 / 2017$ & 31 min e 36 seg \\
\hline V1E8 & Viveirista 1 & Empresa 8 & Barra do Ribeiro/RS & 05/10/2017 & $\begin{array}{l}\text { 1h, } 10 \text { min e } \\
58 \mathrm{seg}\end{array}$ \\
\hline V2E9 & Viveirista 2 & Empresa 9 & Cachoeira do Sul/RS & 06/09/2017 & $44 \mathrm{~min}$ e $53 \mathrm{seg}$ \\
\hline V3E10 & Viveirista 3 & Empresa 10 & $\begin{array}{l}\text { Sant'Ana do } \\
\text { Livramento/RS }\end{array}$ & $18 / 10 / 2017$ & 46 min e 49 seg \\
\hline C1E11 & Comerciante 1 & Empresa 11 & Gramado/RS & $17 / 12 / 2017$ & $14 \mathrm{mim}$ e $05 \mathrm{seg}$ \\
\hline $\begin{array}{l}\text { P1U1 } \\
\mathrm{e} \\
2 \mathrm{I} 1\end{array}$ & Pesquisador 1 & $\begin{array}{l}\text { Universidade } 1 \\
\text { Universidade } 2 \\
\text { Instituto } 1\end{array}$ & $\begin{array}{l}\text { Porto Alegre/RS } \\
\text { São Leopoldo/RS } \\
\text { São Leopoldo/RS }\end{array}$ & 04/10/2017 & 30 min e 43 seg \\
\hline $\begin{array}{l}\text { P2U1 } \\
\text { e } \\
2 \mathrm{I} 1\end{array}$ & Pesquisador 2 & $\begin{array}{l}\text { Universidade } 1 \\
\text { Universidade } 2 \\
\text { Instituto } 1\end{array}$ & $\begin{array}{l}\text { Porto Alegre/RS } \\
\text { São Leopoldo/RS } \\
\text { São Leopoldo/RS }\end{array}$ & $16 / 10 / 2017$ & $54 \mathrm{~min}$ e $07 \mathrm{seg}$ \\
\hline P3O1 & Pesquisador 3 & Órgão 1 & Pelotas/RS & 20/07/2017 & $\begin{array}{l}\text { 1h, } 19 \text { min e } \\
31 \text { seg }\end{array}$ \\
\hline $\mathrm{P} 4 \mathrm{O} 2$ & Pesquisador 4 & Órgão 2 & Maria da Fé/MG & $19 / 07 / 2017$ & 45 min e 26 seg \\
\hline P5O3 & Pesquisador 5 & Órgão 3 & Porto Alegre/RS & 07/08/2017 & 49 min e 39 seg \\
\hline A1 & Azeitólogo 1 & Azeitólogo & Rio de Janeiro/RS & $12 / 10 / 2017$ & $\begin{array}{l}\text { 1h, } 04 \text { min e } \\
01 \text { seg }\end{array}$ \\
\hline Pr1I2 & Presidente 1 & Instituto 2 & Barra do Ribeiro/RS & $05 / 10 / 2017$ & $\begin{array}{l}\text { 1h, } 10 \text { min e } \\
58 \mathrm{seg}\end{array}$ \\
\hline GF1O5 & $\begin{array}{l}\text { Governo } \\
\text { Federal } 1\end{array}$ & Órgão 5 & Porto Alegre/RS & $14 / 09 / 2017$ & $\begin{array}{l}\text { 1h, } 46 \text { min e } \\
45 \text { seg }\end{array}$ \\
\hline GE1O6 & $\begin{array}{l}\text { Governo } \\
\text { Estadual } 1\end{array}$ & Órgão 6 & Porto Alegre/RS & $26 / 09 / 2017$ & $45 \mathrm{~min}$ e $53 \mathrm{seg}$ \\
\hline
\end{tabular}

Fonte: elaborado pelas autoras. 


\section{RESULTADOS: O SISTEMA SETORIAL DE INOVAÇÃO DE AZEITE DE OLIVA DO RIO GRANDE DO SUL}

Nesta seção são descritas e analisadas as informações coletadas na pesquisa de campo e que respondem à questão de quais são e como se comportam os elementos e atores do SSI de Azeite de Oliva do RS.

\section{IV.1. Tecnologia, Constituição dos Negócios e Firmas do Setor}

De acordo com a EMATER/RS-Ascar (2016), na metade sul do estado é onde se encontra a maior produção de azeite de oliva do RS, com destaque para os municípios de Pinheiro Machado/RS, Caçapava do Sul/RS e Canguçu/RS. A SEAPDR/RS (2018) divulgou o Cadastro Olivícola 2017, e nele consta que nesse ano foram produzidos 57873 litros de azeite no Rio Grande do Sul, entre 145 produtores (de pequenos até grandes), distribuídos em 56 municípios. O RS também possui 8 indústrias constituídas, ou seja, 8 lagares, que são os locais de extração e envase do azeite de oliva, e 20 marcas de azeite de oliva estabelecidas, cujos municípios com maior plantio são, respectivamente, Canguçu, Encruzilhada do Sul, Pinheiro Machado, Cachoeira do Sul, Santana do Livramento, Bagé, Caçapava do Sul e Barra do Ribeiro, sendo a serra do sudeste a que apresenta a maior área plantada, com 1778,5 hectares.

Figura 2. Olival e Lagar
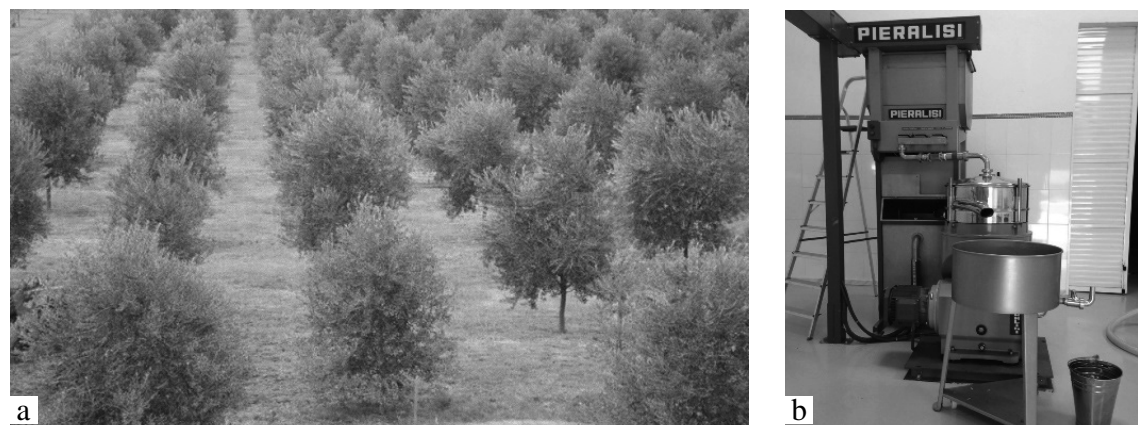

Fonte: a) Olival da Olivas do Sul (2019); b) Parte do lagar do Azeite Batalha (2019).

Na Figura 2, é possível visualizar o olival da Olivas do Sul e parte do lagar do Azeite Batalha. Cabe aqui ressaltar que os equipamentos que compõem esse lagar são da marca italiana Pieralisi, que é considerada uma das melhores do mundo. 
Atualmente, conforme o Governo Federal 1 do Órgão 5, “os maiores produtores do Brasil são 4, e são do Rio Grande do Sul: 1) Azeite Batalha, com 370 hectares; 2) Prosperato, com 300 hectares; 3) Verde Louro, com 300 hectares; e 4) Ouro de Sant'Ana, com 30 hectares”. Esses quatro (4) produtores tem mais de 1000 hectares. Conforme o Governo Estadual 1 do Órgão 6, “a Olivas do Sul teve problemas em duas (2) safras, mas em 2017 voltou a ter produção parelha com a Ouro de Sant'Ana.”. Além disso, há 3 anos a marca RAR está vendendo entre 20 e 30 mil litros por ano de azeite de oliva extra virgem, chileno, no Brasil, para preservar uma fatia do mercado, enquanto não possui produção nacional própria.

De acordo com o Cadastro Olivícola 2017, divulgado pela SEAPDR/RS (2018), a média do tamanho do olival gaúcho é de 23.8 hectares por produtor. Abaixo, no Quadro 2, pode ser observada a distribuição da área cultivada entre os produtores do RS:

Quadro 2. Produtores x Área Cultivada no RS

\begin{tabular}{lcclc}
\hline $\begin{array}{l}\text { Tamanho do Olival } \\
\text { (hectares) }\end{array}$ & $\mathrm{N}^{\circ}$ de Produtores & $\%$ & $\begin{array}{l}\text { Total da Área } \\
\text { (hectares) }\end{array}$ & $\%$ \\
\hline 1 a 10 & 81 & 56 & 326.4 & 9.2 \\
\hline 10.5 a 50 & 48 & 33 & 1225.5 & 35.4 \\
\hline$>50$ & 16 & 11 & 1912.7 & 55.4 \\
\hline TOTAL & 145 & 100 & 3464.6 & 100 \\
\hline
\end{tabular}

Fonte: elaborado pelas autoras.

Os três (3) produtores nacionais, que produzem nos diferentes segmentos da cadeia, desde a muda à produção do azeite, até a indústria, são: 1) Tecnoplanta, com a marca de azeite de oliva extra virgem Prosperato; 2) OlivoPampa, menor produção de mudas, e com a marca Ouro de Sant'Ana; e 3) Olivas do Sul, com a marca de mesmo nome.

Conforme a SEAPDR/RS (2018), através da Nota Técnica ”Cadastro Olivícola 2017”, há atualmente vinte (20) marcas de azeite de oliva no RS: 1) Alma do Segredo (Caçapava do Sul); 2) Batalha (Pinheiro Machado); 3) Bosque Olivos (Cachoeira do Sul); 4) Capolivo (Canguçu); 5) Casa Gabriel Rodrigues (São 
Gabriel); 6) Cerro dos Olivais (Caçapava do Sul); 7) Costa Doce (Dom Feliciano); 8) Costi Olivos (Caçapava do Sul); 9) Dom José (Caçapava do Sul); 10) Dona Esmeralda (São Sepé); 11) Olivae (Piratini); 12) Olivos da Fonte (Formigueiro); 13) Olivas do Sul (Cachoeira do Sul); 14) Olivas do Seival (Candiota); 15) Olivo Brasil (Dom Pedrito); 16) Ouro de Santana (Santana do Livramento); 17) Prosperato (Caçapava do Sul); 18) Quinta Santha Júlia (Encruzilhada do Sul); 19) São Pedro (Caçapava do Sul); e 20) Verde Louro (Canguçu).

No Salão do Azeite Gaúcho (mostra dos azeites de oliva gaúchos), organizado pela SEAPDR/RS e divulgado na Expointer ${ }^{4}$ de 2018, foram acrescidas mais três (3) marcas: 1) Bueno Az 0.2 (Candiota); 2) Casa Albornoz (Santana do Livramento); e 3) Vila do Segredo (Caçapava do Sul). Já no Salão do Azeite Gaúcho, de 2019, foram acrescentadas mais dez (10) marcas: 1) Alto dos Olivos (Barra do Ribeiro); 2) Casa Alfaro (Candelária); 3) Capela de Santana (Sentinela do Sul); 4) Coimbra Martins Costa (Rosário do Sul); 5) Kór (Glorinha); 6) La Pataca (São Francisco de Paula); 7) Milonga (Triunfo), 8) Nina (Rosário do Sul); 9) Quinta da Estância (Viamão); e 10) Terrapampa (Bagé).

\section{IV.2. Mercado}

Conforme Xiong et al. (2014), a produção e o comércio globais de azeite de oliva são grandes e significativos, especialmente na região do mediterrâneo, incluindo o Norte da África e o Oriente Médio, sendo o valor da produção global em torno de 11 bilhões de dólares. Paggi et al. (2015) relatam que o consumo mundial de azeite de oliva aumentou a partir da década de 1990, para além dos mercados tradicionais europeus, à medida que os consumidores de todo o mundo se conscientizavam dos benefícios nutricionais e de saúde do azeite de oliva. Para esses autores, embora a União Européia ainda produza 75\% do azeite global, uma parcela crescente é representada pelos chamados países produtores do "Novo Mundo”, entre eles Estados Unidos, Austrália, Argentina e Chile.

De acordo com Wrege et al. (2015), a demanda pelo azeite de oliva tem aumentado mundialmente, principalmente no Brasil, elevando a necessidade de expansão da área cultivada. Porém, por não existir mais espaço nas regiões tradicionalmente produtoras, há necessidade de procurar novas áreas. Nessa busca, a tendência é de que a cultura venha a ocupar zonas marginais e, assim, surge a

4 Feira agropecuária de destaque nacional e internacional, realizada em Esteio/RS. 
necessidade de desenvolver novos cultivares. Esses autores identificaram áreas marginais para plantio no Brasil, baseando-se em pontos georreferenciados nas regiões produtoras da Europa, Estados Unidos, Austrália e América Latina (Chile, Argentina e Uruguai). Os autores também mencionam que, atualmente, o cultivo está sendo intensificado na Espanha, na Itália, em Portugal, no Chile, na Austrália, nos Estados Unidos (Califórnia), na Argentina e no Uruguai.

Na Figura 3 estão expostos, de forma gráfica, os dados ${ }^{5}$ dos três maiores países produtores, consumidores, importadores e exportadores de azeite de oliva, respectivamente, no ano de 2017, divulgados pelo COI (2017). No gráfico, é possível observar que a Espanha se destacou como o principal país produtor de azeite de oliva (1286.6 mil toneladas), seguida pela Grécia (195 mil toneladas) e pela Itália (182.3 mil toneladas); os países que mais consumiram azeite de oliva foram a Itália (514 mil toneladas), a Espanha (457.2 mil toneladas) e os EUA (315 mil toneladas); os EUA se destacou como o país que mais importou o produto (305 mil toneladas), seguido da Itália (80 mil toneladas) e do Brasil (59.5 mil toneladas); e a Espanha se destacou na exportação do produto (284.8 mil toneladas), seguida da Itália (214.8 mil toneladas) e da Tunísia (85.5 mil toneladas).

O Governo Federal 1 do Órgão 5 mencionou que "99,9\% do azeite consumido no Brasil é importado”. O Pesquisador 5 do Órgão 3 reforçou que “a nossa produção representa 1/1000 da importação, e por isso, a ideia de mercado está escancarada na nossa frente”. A produção nacional ainda é muito pequena, mas deve ser incrementada nos próximos anos, com a maturação dos olivais. Em função disso, os azeites brasileiros estão chegando no mercado com preços maiores que a média internacional, embora o valor do produto não seja determinado, somente, pela qualidade ${ }^{6}$ do azeite de oliva. Tem outros fatores, como, por exemplo, investir

5 Os números da Itália são curiosos, pois este país produziu 182.3 mil toneladas, importou 80 mil toneladas e exportou 214.8 mil toneladas. Assim, restariam 47.5 mil toneladas para consumo interno, enquanto que o COI informou que o consumo deste país foi de 514 mil toneladas. Esse desencontro de dados pode sugerir algo relacionado à falsificação do produto, visto que essa prática não é incomum no setor. Mueller (2012) relata que muitas fraudes de azeite de oliva envolvem a mistura de óleos vegetais de baixa qualidade, aromatizados e coloridos com extratos de plantas e vendidos em latas e garrafas decoradas com bandeiras italianas e imagens do vulcão Vesúvio, com nomes de produtores imaginários. Outras fraudes, mais sofisticadas, ocorrem em laboratórios, onde azeites de oliva mais baratos são processados e misturados de forma difícil de se detectar com testes químicos. O autor também menciona que devido ao tamanho e a internacionalização do setor agroalimentar, o controle contra fraudes é muito difícil, sendo o azeite de oliva um dos produtos alimentares mais adulterados na União Europeia. A exemplo, segue link de notícia recente sobre fraude no Brasil: http://www.agricultura.gov.br/noticias/ministerio-proibe-venda-de-azeites-de-oliva-de-seis-marcas O azeite de oliva extra virgem tem no máximo 2 anos de vida útil, conservado em temperatura 
na marca, através de uma equipe de marketing, para desenvolvê-la, fazer promoções, participar de feiras, tornar esse azeite, realmente, reconhecido. Além disso, é fundamental ter uma garrafa bonita, um rótulo agradável e um nome aceitável.

Figura 3. Mercado Mundial de Azeite de Oliva

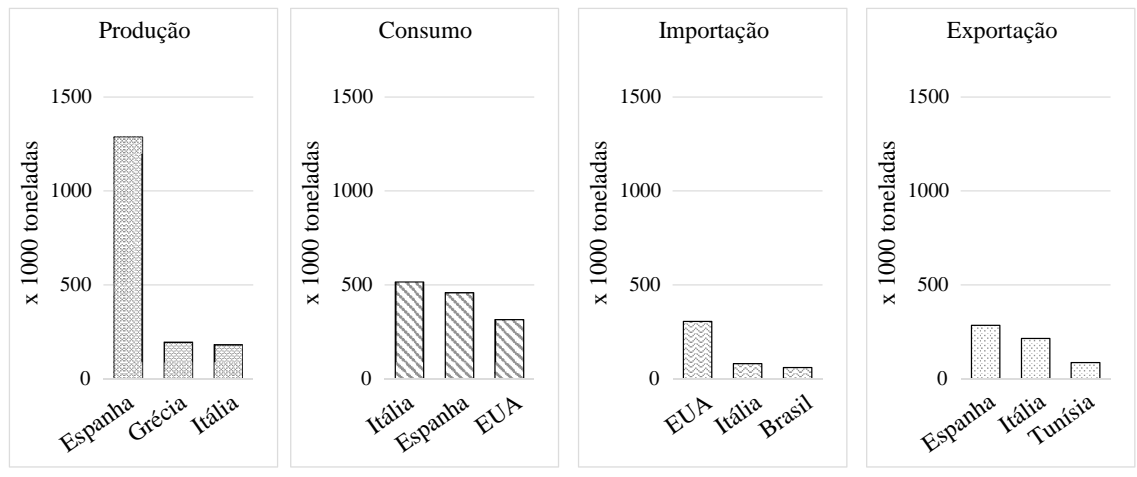

Fonte: elaborado pelos autores.

\section{IV.3. Instituições e Organizações}

Para facilitar a leitura, abaixo, no Quadro 3, estão apresentados os principais acontecimentos relacionados ao setor de azeite de oliva, de forma cronológica, bem como as respectivas instituições e organizações do setor, sobretudo no RS:

ambiente. Em geral, os produtores de excelência concedem apenas 18 meses de validade, para o azeite, após o seu envase. As instruções normativas do mundo e a do Brasil, especificamente, chegam a dar 3 anos de validade para ele, após o engarrafamento, porque ele não estraga, ele se oxida. E, conforme vai se oxidando, vai perdendo o valor nutricional. Ocorre que os azeites importados, muitas vezes, são engarrafados no destino, e a data da extração de azeite não é informada. Além disso, não se tem conhecimento das condições em que ele é armazenado e transportado, desde a sua extração até o envaze, o que pode comprometer a sua qualidade, inclusive porque o azeite de oliva é sensível à luz, ao calor e ao oxigênio. 


\section{Quadro 3. Acontecimentos do Setor de Azeite de Oliva}

\begin{tabular}{|c|c|}
\hline Ano & Acontecimento \\
\hline 1939 & A SEAPDR/RS importa e testa variedades de oliveiras da Argentina. \\
\hline 1947 & $\begin{array}{l}\text { É sancionada a Lei Estadual } n^{\circ} 59 / 47 \text {, que oferecia incentivos fiscais e prêmios } \\
\text { para o produtor que contribuísse para o plantio dos primeiros } 1000 \text { hectares de } \\
\text { oliveiras no RS. }\end{array}$ \\
\hline 1948 & $\begin{array}{l}\text { A SEAPDR/RS cria o Serviço Oleícola, com propósitos de supervisionar e } \\
\text { orientar os trabalhos de fomento e pesquisa, que foi até } 1960 \text {. }\end{array}$ \\
\hline 1960 a 2000 & $\begin{array}{l}\text { Não houve ações dos governos federal e estadual, e nem da iniciativa privada, } \\
\text { nesse período. }\end{array}$ \\
\hline 2000 a 2010 & Nesse período ocorreram plantios, testes, observações e capacitações. \\
\hline 2002 & $\begin{array}{l}\text { Foi realizado o Fórum de Fruticultura na metade Sul do RS, com palestras sobre } \\
\text { olivicultura. }\end{array}$ \\
\hline 2005 & $\begin{array}{l}\text { Produtores de Caçapava do Sul/RS, vinculados à Associação Olisul, recebem a } \\
\text { verba de } 300 \text { mil reais da SEAPDR/RS. } \\
\text { As oliveiras começaram a ser plantadas, nessa fase nova, no RS, por esse grupo } \\
\text { de produtores. }\end{array}$ \\
\hline 2006 & $\begin{array}{l}\text { O Ministro da Agricultura João Roberto Rodrigues criou um grupo de trabalho } \\
\text { para fomentar a olivicultura no Brasil. } \\
\text { Pesquisadores da EMBRAPA Clima Temperado, de Pelotas/RS, em conjunto } \\
\text { com a EMBRAPA Semiárido, EPAGRI, INIA (Uruguai), IAPAR, EPAMIG, } \\
\text { UFPEL, UCS, UERGS, EMATER/RS-Ascar, Câmara de Comércio Portuguesa } \\
\text { no Brasil/RS e Empresa Agromillora S.A., iniciaram ações de pesquisa para } \\
\text { avaliar a viabilidade do cultivo comercial da oliveira na região Sul do Brasil. }\end{array}$ \\
\hline 2008 & $\begin{array}{l}\text { Criação do Grupo Técnico de Pesquisa e Extensão, com a participação de } \\
\text { técnicos da EMATER/RS-Ascar, da Faculdade de Agronomia da UFRGS, } \\
\text { técnicos da EMBRAPA, FEPAGRO e consultores privados. } \\
\text { O Brasil, oficialmente, produziu o primeiro azeite de oliva extra virgem, no } \\
\text { município de Maria da Fé/MG, na Serra da Mantiqueira. }\end{array}$ \\
\hline 2010 a 2016 & $\begin{array}{l}\text { Houve a expansão de área cultivada. } \\
\text { Ocorreu a colheita de azeitonas, no RS, gerando a produção do azeite de oliva. }\end{array}$ \\
\hline 2012 & $\begin{array}{l}1^{\text {a }} \text { Abertura Oficial da Colheita, realizada na Olivas do Sul, em Cachoeira do } \\
\text { Sul/RS. } \\
\text { Criação da Câmara Setorial da Olivicultura, vinculada a SEAPDR/RS, para } \\
\text { fomentar o setor. }\end{array}$ \\
\hline
\end{tabular}


2013 2a Abertura Oficial da Colheita, realizada na Tecnoplanta, em Caçapava do Sul/RS.

$2014 \quad 3^{\text {a }}$ Abertura Oficial da Colheita, realizada no Azeite Batalha, em Pinheiro Machado/RS.

$2015 \quad 4^{\text {a }}$ Abertura Oficial da Colheita, realizada na Olivopampa, em Santana do Livramento/RS.

Criação do Programa Estadual de Olivicultura, Pró-Oliva, vinculado a SEAPDR/ RS, para fomentar o setor.

$2016 \quad$ 5a Abertura Oficial da Colheita, realizada na Tecnoplanta, em Barra do Ribeiro/RS Redução do ICMS* do azeite de oliva no RS.

2017 6 6 abertura Oficial da Colheita, realizada na Prosperato, em São Sepé/RS.

Criação do Instituto Brasileiro da Olivicultura (IBRAOLIVA).

Coleta de dados para a elaboração do $1^{\circ}$ Cadastro Olivícola do RS (realizada pela

SEAPDR/RS, com a colaboração da EMATER/RS-Ascar e do IBRAOLIVA).

2018 Criação da Olivoteca (Instituto Brasileiro para promoção do azeite de oliva extra virgem), para promover e difundir a cultura e consumo do azeite de oliva extra virgem no Brasil.

$7^{\mathrm{a}}$ Abertura Oficial da Colheita, realizada no dia 02 de março, na propriedade Quinta Santha Júlia, em Encruzilhada do Sul/RS.

Divulgação do Cadastro Olivícola 2017, na abertura oficial da colheita de 2018.

Os dados foram publicados no site da SEAPDR/RS.

2019 8 Abertura Oficial da Colheita, realizada no dia 15 de março, na propriedade Olivais da Fonte, em Formigueiro/RS.

* Em 27/10/2016, o governador do RS, José Ivo Sartori, através do decreto n 53275, reduziu o ICMS (Imposto sobre Operações relativas à Circulação de Mercadorias e Prestação de Serviços de Transporte Interestadual e Intermunicipal e de Comunicação) dos estabelecimentos fabricantes de azeite de oliva do estado, nas vendas do produto dentro do RS, de $18 \%$ para $7 \%$ e, nas vendas para fora do estado, onde o ICMS era de $12 \%$ em MG, PR, RJ, SC e SP, e 7\% nos demais estados, para 4\%. Fonte: elaborado pelos autores.

Devido à proximidade geográfica e ao clima do Uruguai ser semelhante ao do RS, estão se acompanhando as práticas dos produtores uruguaios, pois esse país iniciou os investimentos nesse setor, cerca de 10 anos antes que o RS e, por isso, está na frente, possuindo, inclusive, um painel de avaliação sensorial, acreditado pelo $\mathrm{COI}^{7}$. Nesse sentido, o MAPA vem fazendo pesquisas sobre material genético das

7 Conselho Oleícola Internacional: é a organização internacional dedicada ao azeite e às azeitonas de mesa, criada em Madrid, na Espanha, em 1959, com ciência das Nações Unidas. O COI desenvolveu um sistema para avaliação organoléptica do azeite, que pode ser percebida pelos sentidos, a fim de determinar a qualidade sensorial e, consequentemente, comercial de um azeite. 
oliveiras, mas como o Brasil ainda não tem um padrão genético, ainda é muito cedo para dizer quais são as melhores variedades para se cultivar em cada região do país.

Segundo Urieta et al. (2018), o setor olivícola uruguaio surgiu, comercialmente, a mais de 70 anos, mas a produção de azeite de oliva foi impulsionada somente a partir de 2002. Atualmente, esse país possui em torno de 10000 hectares cultivados e mais de 30 marcas de azeite de oliva, inclusive, com algumas delas premiadas internacionalmente.

\section{IV.4. Processo de Geração e Difusão do Conhecimento/Inovações}

O método de extração de azeite de oliva foi evoluindo com o tempo. Desde os anos 90, elaboram-se azeites de acordo com o grau de maturidade da fruta. Ou seja, na colheita precoce, no amadurecimento ou na colheita madura. Elaboram-se azeites, também, pela variedade da fruta ou pela mistura de diversas variedades. Os azeites de oliva possuem atributos sensoriais diferentes, como o frutado, maduro ou verde, mais intenso ou menos intenso, sentido através do olfato e do paladar. Nesse quesito, os europeus se destacam, pois têm experiência com o azeite de oliva e suas sutilezas a séculos. Já Ambrosini et al. (2017) mencionam a importância de promover ações educativas e promocionais junto aos consumidores brasileiros, para estimular o consumo do azeite de oliva e o desenvolvimento da olivicultura no Brasil.

Esses atributos vêm chamando a atenção dos consumidores, e esses produtos tem ganhado mercado. Para Ambrosini et al. (2017), o consumo de azeite de oliva vem crescendo no Brasil, mas poucas pesquisas têm analisado os critérios de escolha que guiam a compra dos consumidores. $\mathrm{O}$ azeite também apresenta distintas características de amargor, sentido na língua, e picor, sentido na garganta. O amargor e o picor do azeite de oliva estão relacionados ao oleocanthal, que é uma substância presente na azeitona. Quanto mais verde ela estiver, menor a quantidade de azeite produzida e, consequentemente, maior o custo de produção, mas mais rica é em oleocanthal, o que traz muitos benefícios à saúde. O que agrega valor ao azeite são estas características, que vão muito além da acidez e do perfil de ácidos graxos.

O Governo Federal 1 do Órgão 5 mencionou que "todas as fábricas do parque industrial do RS já saíram de um nível tecnológico mais avançado”. Essa tecnologia foi desenvolvida no ano 2000, pela marca Pieralisi, que é italiana, dando um salto tecnológico na época. O Pesquisador 2 das Universidades 1 e 2 e do Instituto 1 complementou que “a Pieralisi criou uma máquina de extração de azeite, 
que é uma pequena indústria, com fluxo único, onde a azeitona é lavada, colocada inteira na máquina, para seguir uma linha de produção, baseada em centrifugação”.

O Comerciante 1 da Empresa 11 mencionou que "a Espanha é o país que mais desenvolve tecnologia para a produção de azeite de oliva. Eles são os maiores e os melhores produtores e tem azeites muito bons”.

\section{DISCUSSÃO}

Por falta de manejo, tecnologia e, até mesmo, de profissionais habilitados para adaptar o conhecimento europeu de produção de oliveiras para o clima e solo brasileiros, no passado, o cultivo de oliveiras somente deslanchou no RS por volta de 2010, o que ainda é muito recente. Mesmo assim, a cada safra, o conhecimento foi melhorando, pela experiência continuada, o que foi fundamental para se atingir um produto de qualidade. A metade sul do RS e a Serra da Mantiqueira são os dois (2) centros no Brasil que estão se destacando na produção de azeite de oliva extra virgem. O RS está produzindo azeite de oliva em maior quantidade e em melhor qualidade que a região da Serra da Mantiqueira, em função de condições climáticas e de solo. Diferentemente do RS, a região da Serra da Mantiqueira não tem tanta área para ampliação da produção, em função do relevo típico de região serrana e, por isso, essa região também é de difícil mecanização. Rodrigues (2016) também mencionou que, por ser acidentada, a região da Serra da Mantiqueira é de difícil mecanização e, consequentemente, isso impede uma produção em larga escala. Já o RS possui cerca de 3 milhões de hectares de áreas recomendáveis para o cultivo de oliveiras, distribuídas, na maior parte, no Pampa Gaúcho. Segundo o IBRAOLIVA (2019), o mercado oleícola brasileiro possui 330 agricultores e 80 marcas de azeite de oliva.

Atualmente, o Brasil importa 99.9\% do azeite de oliva consumido. O país é um dos maiores importadores mundiais desse produto. O produtor brasileiro ainda tem uma produtividade baixa devido à parte de seus olivais não terem atingido o auge da sua fase produtiva e, por isso, o produto tem um preço relativamente elevado. No RS, particularmente, dois terços (2/3) dos olivais estão com menos de seis (6) anos, ou seja, não estão no auge da sua fase produtiva, que é aos dez (10) anos. Mas, em geral, a produção nacional está crescendo e o mercado interno está absorvendo os produtos, embora a produção ainda seja insuficiente para atender o mercado, já que vários produtores esgotaram a safra de 2017 antes de acabar o ano. 
Há bastante heterogeneidade quanto ao tamanho e a qualificação do produtor, bem como quanto à busca pelo conhecimento, que, principalmente entre os maiores produtores, veio do exterior (Itália, Portugal, e sobretudo, da Espanha, que é o maior produtor mundial). Particularmente, o RS se espelha muito no Uruguai, ter iniciado o cultivo de oliveiras antes do RS e, principalmente, por também possuir uma olivicultura úmida.

Os produtores desse setor, em geral, não costumam ser agricultores de tradição e, muitas vezes, já possuem outros negócios. Costumam ser empresários urbanos e profissionais liberais, principalmente os que estão plantando as maiores áreas. Nesse caso, a olivicultura passa a ser mais uma fonte de renda e é vista como mais uma alternativa para diversificação dos negócios.

De um modo geral, os maiores produtores possuem lagar e empório próprio, geralmente próximo do olival. Além disso, as marcas mais conhecidas costumam estar expostas em lojas especializadas do ramo. Percebe-se também que os maiores produtores estão inseridos no mundo virtual, preocupados em divulgar o seu produto e os benefícios do azeite de oliva por meio de sites próprios, incluindo a possibilidade de vendas on line. Também possuem páginas em redes sociais, como o Facebook.

Geralmente, os pequenos produtores não contratam engenheiro agrônomo ou técnico agrícola, por não terem recursos para isso ou, até mesmo, por considerarem ser desnecessário esse conhecimento. Eles realmente acreditam que ao plantar as oliveiras, vão conseguir colher as azeitonas. Depois disso, os arranjos ${ }^{8}$ são diversos. Nem sempre os pequenos produtores extraem o próprio azeite. Já os maiores produtores, além de extraírem o próprio azeite, possuem marcas próprias e, na maioria dos casos, são pessoas que viajam bastante para fora do país, buscam tecnologia no exterior e, em função dos maiores investimentos, se qualificaram melhor, fazendo cursos, trazendo profissionais do exterior e enviando funcionários para estudar fora do país.

8 Dependem da modalidade que o produtor escolher, em função do capital que pretende investir e do seu perfil para os negócios. O produtor pode vender a fruta in natura; pode produzir azeitona de mesa; pode optar em terceirizar o serviço do lagar, entregando as frutas para o beneficiamento do azeite de oliva e retirando o produto já engarrafado, pronto para ser vendido; e pode instalar o seu próprio lagar, para, inclusive, processar azeite de outros produtores. Outra decisão que o produtor deve tomar é com relação ao tipo de azeite que vai produzir, podendo ser monovarietais ou blends. 
Há milhares de anos se produz azeite de oliva no mundo, mas a tecnologia de produção mudou há cerca de 30 anos (até no máximo 40 anos). E, no ano 2000, foi desenvolvida uma máquina de extração de azeite, que é uma pequena indústria, com fluxo único. O RS já iniciou sua produção com essa nova sistemática, inclusive os pequenos produtores, o que contribuiu para a qualidade dos azeites produzidos no estado, pois o nível tecnológico é mais avançado. Essa nova forma de produção está contribuindo para essa indústria gaúcha fazer um produto de maior qualidade, o que é indicado pela existência de marcas gaúchas premiadas em salões internacionais.

O RS produz um azeite de oliva extra virgem de qualidade, o que está relacionado com a forma com que se conduziu o olival, desde a escolha das mudas; com as questões de clima e solo da região produtora; com a sanidade e a maturação da fruta e, consequentemente, período certo da colheita precoce, cuja fruta não amadurece no pé; com as condições e com o tempo de transporte das azeitonas até chegar ao lagar; ao cuidado no processamento do azeite, com máquinas que trabalhem com foco em qualidade e não no volume; com as condições de higiene do lagar e com o cuidado no armazenamento do produto.

O valor do produto não é determinado, somente, pela qualidade do azeite de oliva. Outros fatores, que vão além da tecnologia, como investimento na marca, realização de promoções e participação em feiras para tornar o azeite realmente reconhecido, são importantes. Além disso, é fundamental ter uma garrafa bonita, um rótulo agradável, e um nome aceitável, para melhor transacionar o produto no mercado.

Hoje, a análise sensorial é a mais importante para identificar se um azeite de oliva é extra virgem ou não, e isso é muito importante de ser divulgado para o consumidor, para que consiga identificar um azeite de oliva efetivamente de qualidade. Como o Brasil ainda não tem um painel sensorial formado, creditado junto ao COI, com provadores capacitados que possam fazer a análise sensorial de azeite de oliva, a análise sensorial não é obrigatória. Já se sabe que o grupo de pessoas que vão fazer parte do primeiro painel estão sendo treinadas. E, a partir do momento que vigorar o anexo 2, análise sensorial, da normativa 01, do MAPA, de 2012, os produtores gaúchos já poderão estar alinhados. Além disso, a formação de um painel sensorial deve ser um elemento positivo na redução da entrada de produtos fraudados no mercado brasileiro.

No caso da maioria do azeite de oliva importado pelo Brasil, após ser extraído, é levado para um reservatório, e, geralmente, não é engarrafado na ori- 
gem. Esse azeite é transportado de navio, dentro de um container, até o porto, e depois de ser liberado na alfândega, é levado ao distribuidor para ser engarrafado e conduzido até o ponto de venda. Não se sabe ao certo as condições às quais esse produto é submetido, até que ponto sua qualidade é comprometida - uma vez que ele é muito sensível à luz, ao oxigênio e ao calor. Já no caso do azeite nacional brasileiro, a azeitona é colhida de forma precoce, da árvore, vai direto para o processamento, e o azeite é engarrafado e distribuído para os pontos de vendas. O azeite nacional é mais jovem, apresenta mais frescor e mais aroma. A diferença está no manejo com a fruta e no tempo de extração do azeite até chegar à loja, para estar disponível para o consumidor.

Recentemente, o MAPA regulamentou um fungicida, um inseticida e um herbicida para a cultura da oliveira, o que é um avanço, mas devido à escala ser pequena, a indústria demonstrou pouco interesse em produzir esses produtos. Conforme constatou Rodrigues (2016), os produtores continuam à mercê das pragas ou acabam utilizando defensivos agrícolas de outras culturas, para não perder a produção, o que não é permitido pelo MAPA. O MAPA, no país, normatiza, organiza e fomenta a cadeia produtiva do azeite de oliva, juntamente com a SEAPDR/RS, que no estado, atua principalmente através da Câmara Setorial da Olivicultura e do programa estadual de olivicultura Pró-Oliva. Ambos promovem eventos, organizam palestras, realizam cursos e encontros.

Já a EMBRAPA e a EMATER/RS-Ascar, juntamente com os demais órgãos de pesquisa, viabilizam informações do setor, principalmente, a nível de campo. Além disso, há algumas parcerias com universidades, através de projetos de pesquisa, especialmente com os cursos de gastronomia, engenharia de alimentos e agronomia. Ficou claro que as instituições envolvidas no setor olivícola, tanto nacionais quanto estaduais ou privadas, não estão competindo entre si. Elas se complementam. Cabe salientar que a iniciativa pública é muito importante, mas que apenas ela não é o suficiente para desenvolver a cadeia olivícola, por isso o produtor recorre a iniciativas privadas, como a busca de informações com consultores particulares.

Constatou-se que é unânime, entre os entrevistados que as associações de olivicultores do RS ainda não têm uma atuação efetiva no estado. Essa constatação também está presente no estudo de Rodrigues (2016), o qual informa que os entrevistados, apesar de reconhecerem as associações Olisul e ARGOS, entendiam que elas eram pouco atuantes. 
A maioria dos produtores do RS, independentemente de serem maiores ou menores, não utilizaram fontes de financiamentos bancários para aquisição do olival e também utilizam seus recursos próprios para a manutenção do olival. Além disso, esses produtores não costumam contratar seguro do olival, por esse produto ainda ter um preço elevado no mercado.

Percebeu-se que todos os entrevistados que disponibilizaram tempo para participar da entrevista o fizeram em prol da divulgação e do desenvolvimento da olivicultura nacional, uma vez que se tem um longo caminho a percorrer, pois é uma cultura que não tem tradição no país. É notório que não exista interesse por parte de grandes empresas, tanto nacionais, como as produtoras de óleo de soja, quanto internacionais, como as produtoras de azeite de oliva, em que o Brasil comece a produzir azeite de oliva, devido à concorrência de mercado. Também foi consenso geral que é necessário investir mais em pesquisas, principalmente a nível de campo, para estabilizar a produção.

Nesse setor, foram identificadas inovações, como a utilização de calcário para corrigir a acidez e os níveis de alumínio no solo, e a elaboração de azeites com sensoriais distintos, através da maturação da fruta, pela colheita precoce e tardia, da variedade da fruta e dos fatores climatológicos; na indústria, a extração do azeite de oliva ocorre através da utilização de uma máquina com processo único e contínuo. Também há a utilização de talco alimentício na produção do azeite de oliva extra virgem, e a possibilidade de extração do azeite de oliva através de máquinas de ultrassom; no comércio, ocorre a comercialização do azeite de oliva na internet, através do site do próprio produtor ou de lojas especializadas do ramo, além da utilização de redes sociais para a divulgação de materiais informativos do setor e do produto propriamente dito.

Na Figura 4, apresenta-se o desenho do SSI de Azeite de Oliva, tanto do RS quanto do Brasil, com as interações de seus principais atores. Esse SSI tem como eixo principal o fluxo da produção do azeite de oliva, que ocorre desde a produção das mudas de oliveira, pelos viveiristas, até o produto chegar ao consumidor final. Acrescenta-se que o COI não está incluído nesse desenho, pois o Brasil ainda não é membro desse órgão internacional.

Durante o ano de 2017, foi criada a Olivoteca, e ocorreu a coleta de dados para compor o primeiro cadastro olivícola do RS. Esse trabalho foi elaborado pela SEAPDR/RS, com a colaboração da EMATER/RS-Ascar e do IBRAOLIVA, com o objetivo de apresentar dados atualizados da distribuição de áreas plantadas, do número de produtores por região e por municípios, e outras informações relavantes 
do setor olivícola gaúcho. A partir do Cadastro Olivícola 2017 foi possível obter uma radiografia mais completa do setor e, com isso, poder elaborar políticas de fomento. Os dados coletados foram divulgados na abertura oficial da colheita de 2018, e estão divulgados no site da SEAPDR/RS. Esses dados apontam crescimento da área plantada, chegando a 3464 hectares em 2017, superando a meta de 3000 hectares estabelecida pelo Pró-Oliva, para o final de 2018, o que representa o crescimento desta cultura no estado. Segundo a SEAPDR/RS (2018), a área plantada com oliveiras deve chegar a 4,5 mil hectares no Rio Grande do Sul até o final de 2018.

Figura 4. Desenho do SSI de Azeite de Oliva

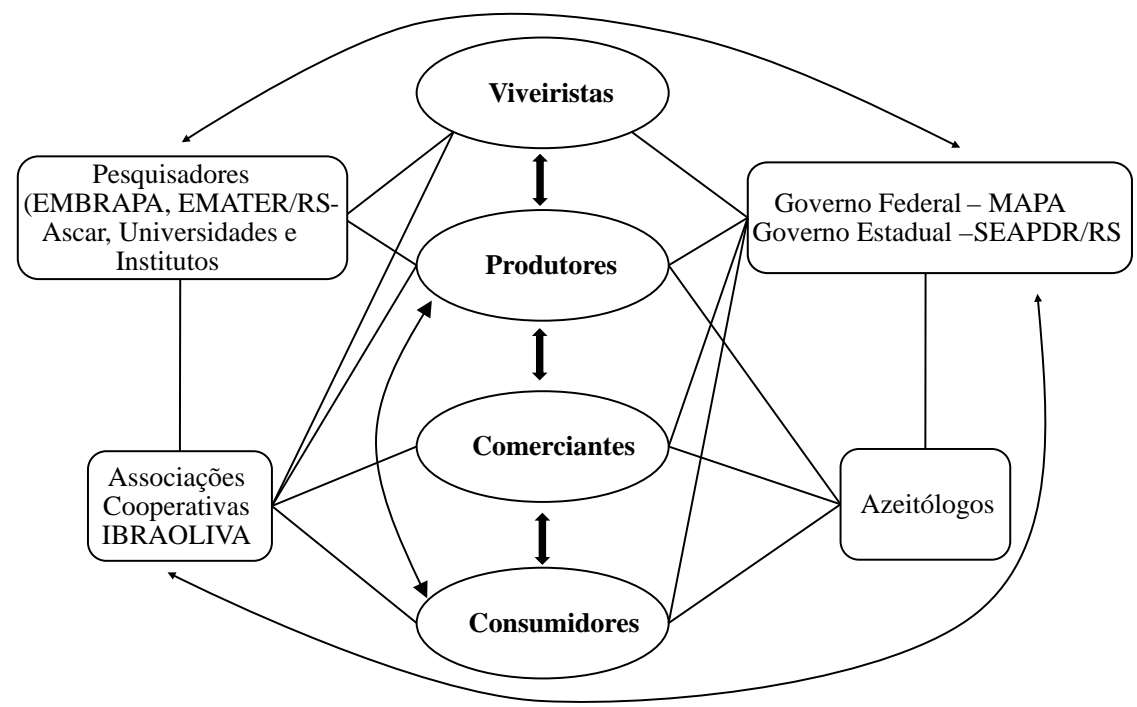

Fonte: elaboração própria.

\section{CONCLUSÕES}

Este estudo se propôs a responder à seguinte pergunta: "Quais são e como se comportam os elementos e atores que explicam o desenvolvimento do Sistema Setorial de Inovação (SSI) de azeite de oliva no RS?”.

A abordagem teórica de SSI contribuiu para a análise do setor de azeite de oliva no RS, que é composto por empresas, principalmente privadas, que atuam 
no desenvolvimento e fabricação de azeites de oliva e na geração e utilização de tecnologias. Esse recorte analítico permitiu identificar quatro elementos: o papel das instituições/organizações, o papel do mercado, o papel do processo de geração e difusão do conhecimento/inovações e o papel da tecnologia, da constituição dos negócios e das firmas do setor nesse processo.

Os atores do SSI analisado possuem funções distintas: produtores, viveristas, pesquisadores, comerciantes, bancos, institutos, consultores técnicos, órgãos do governo federal e estadual. Pode-se afirmar que há um relacionamento entre esses atores que permite a troca de informações a respeito de novas tendências e experiências para melhorar a produtividade, pois entendem que ações coletivas que promovam o crescimento e reconhecimento do setor são importantes e que há mercado para todos. Prova disso é que a maioria dos produtores - de pequenos a grandes -, fazem parte do IBRAOLIVA, que além de ter sido criado para representar melhor o setor, também pretende promover a cadeia produtiva do azeite de oliva no país. A exceção está nas associações de produtores do Estado, conforme já mencionado.

O clima e o solo, as condições de manejo do olival, a sanidade da fruta, a colheita precoce, as condições e o tempo de transporte das azeitonas até o lagar e o cuidado no processamento do azeite são diferenciais que garantem qualidade ao azeite gaúcho, comprovada em guias e concursos internacionais. Além desses elementos, o MAPA e a SEAPDR/RS também desempenham papel fundamental no fomento desta atividade, quer seja através da regulamentação do setor, ou nas atividades da Câmara Setorial da Olivicultura e do programa estadual Pró-Oliva, respectivamente.

Os fluxos de conhecimentos tecnológicos dos atores também foram e são fundamentais para o desenvolvimento deste SSI. A busca do conhecimento, inicialmente externo - principalmente dos EUA, da Itália, de Portugal e da Espanha, que é o maior produtor mundial de azeite de oliva -, permitiu que, em determinado momento, esse conhecimento fosse construído internamente pelas instituições do SSI. No caso dos produtores menores, o conhecimento é obtido, principalmente, por meio de técnicos da EMATER/RS-Ascar e da EMBRAPA, e de conhecidos do ramo, destacando a importância das instituições no processo de difusão de conhecimentos tecnológicos. Além disso, os produtores do RS se espelham muito no Uruguai, pois este país possui uma olivicultura de clima úmido e iniciou o cultivo há mais tempo. Portanto, o papel das instituições é relevante, não apenas para a constituição, mas para a continuidade desse processo. Como efetivamente se quer desenvolver um setor produtor de um produto de alto valor agregado, focar na possibilidade dessas instituições continuarem promovendo o desenvolvimento no setor é fundamental. 
Percebeu-se, na pesquisa de campo, que as firmas conseguem absorver o conhecimento tecnológico. A própria constituição das firmas, nesse sistema, é muito peculiar. $\mathrm{O}$ fato de serem negócios de pessoas que já têm experiência com outros negócios, cuja olivicultura é uma segunda atividade, permite o investimento no longo prazo, o que favorece as oliveiras, que atingem a maturidade em 10 anos. Essa dinâmica não é determinada pela obtenção de crédito bancário, para adquirir o olival e mantê-lo, mas, sim, por recursos financeiros próprios das firmas. E o seguro do olival ainda é pouco utilizado, em função de seu valor elevado.

Entende-se, portanto, que o SSI de Azeite de Oliva no RS constituiu-se com mais vigor recentemente e ainda está em desenvolvimento, pois dois terços (2/3) dos olivais do RS estão com menos de seis (6) anos, ou seja, não estão no auge da sua fase produtiva, que é aos dez (10) anos. Por conta disso, os produtores ainda apresentam baixa produtividade. Ademais, ainda falta maior domínio sobre a produção, pois há anos em que não há produção.

Para que o setor se fortaleça, é importante um painel sensorial formado e atuante; o Brasil ser membro do COI; aumentar a fiscalização do azeite de oliva, sobretudo dos importados, visando reduzir a comercialização de azeites fraudados; priorizar as pesquisas, principalmente no campo, para aumentar a produtividade e estabilizar a produção através do cultivo de varietais que melhor se adaptam à olivicultura úmida do RS e aperfeiçoar o olival para permitir a mecanização. O fortalecimento do IBRAOLIVA também é importante para organizar e promover a cadeia da vitivinicultura brasileira. Quiçá, no futuro próximo, com a tradição da produção do azeite de oliva já constituída, possa ser consolidada a indicação geográfica (IG), como já mencionado por Rodrigues (2016). Nesse caso, os produtores podem ser autorizados pelo MAPA a colocar um selo no rótulo no produto, como no caso do vinho gaúcho, produzido no Vale dos Vinhedos, que possui Indicação de Procedência (IP ${ }^{9}$ ) e Denominação de Origem (DO $\left.{ }^{10}\right)$.

Como o trabalho de Rodrigues (2016) foi anterior ao decreto estadual de redução do ICMS, o autor não mencionou esse fato, que representou um avanço significativo para o setor, principalmente para as empresas maiores, resultando em uma diminuição importante na cobrança de impostos. O autor também não reportou a criação do IBRAOLIVA, cujo objetivo é representar melhor o setor e, também,

9 Porque o nome do local se tornou conhecido por produzir, extrair ou fabricar determinado produto ou prestar determinado serviço.

10 Porque o nome do local passou a designar produtos ou serviços, cujas qualidades ou características podem ser atribuídas a sua origem geográfica, agregando valor ao produto. 
promover a cadeia produtiva do azeite de oliva no país, até porque o instituto foi criado no dia 30/08/2017.

Embora Rodrigues (2016) tenha apontado a futura elaboração de um cadastro oficial olivícola do RS, em 2016 não havia data prevista para isso ocorrer. Segundo o autor, o RS possuía 160 produtores, em 55 municípios, 8 indústrias, 13 marcas de azeite de oliva, com a expectativa de chegar aos 3000 mil hectares plantados até 2018. Com o Cadastro Olivícola 2017, elaborado pela SEAPDR/RS, elaborado pela EMATER/RS-Ascar e IBRAOLIVA, constatou-se que o RS possui 145 produtores, distribuídos em 56 municípios, 8 indústrias constituídas e 20 marcas de azeite de oliva estabelecidas. Os dados apontam crescimento da área plantada, chegando a 3464 hectares em 2017, superando a meta de 3000 hectares estabelecida pelo Pró-Oliva, para o final de 2018, o que representa o crescimento desta cultura no Estado. Isso também pode ser observado pelo aumento do número de marcas do produto, que no RS chegam a 33, conforme o Salão do Azeite Gaúcho de 2019.

Como limitações do estudo, destaca-se a não possibilidade de generalização dos resultados, bem como os limites relativos à isenção da pesquisadora quanto da realização das entrevistas e obtenção dos dados. A proposta de compreender o SSI do azeite de oliva do RS, portanto, não se esgota nessa pesquisa. Sugeremse futuros estudos que consigam abranger todos os atores envolvidos neste setor do RS, como a realização de uma pesquisa tipo survey, por exemplo, bem como estudos que objetivem compreender a dinâmica da produção de azeite de oliva no âmbito nacional, comparando a estrutura desse setor com outros países ou regiões internacionais que já possuem tal setor consolidado e competitivo. Também mostrase interessante um estudo comparativo entre SSI de diferentes produtos de elevado valor agregado no agronegócio do RS.

\section{REFERÊNCIAS BIBLIOGRÁFICAS}

Albin, A., \& Villamil, J. (2003). Aceite de oliva: tradicional sabor mediterráneo, rejuvenecido en tierras Uruguayas. Montevideo: Editora de Vecho.

Albin, A., \& Villamil, J. (2003). Aceite de oliva: tradicional sabor mediterráneo, rejuvenecido en tierras Uruguayas. El País Agropecuario, Julio, 25-28.

Azeite Batalha, produzido no Brasil - Galeria (2019). Disponível em https://www. azeitebatalha.com.br/galeria.

International Olive Council (n.d.). Economic Affairs \& Promotion Unit. Disponível em http://www.internationaloliveoil.org/estaticos/view/132-world-table-olive-figures. 
Caye, A. (2018). O Desenvolvimento de um Sistema Setorial de Inovação: a produção de azeite de oliva no Rio Grande do Sul. Dissertação de Mestrado no Programa de Pós-Graduação em Economia (PPGE), Universidade do Vale do Rio dos Sinos.

Coutinho, E. F., Jorge, R. O., Haerter, J. A., \& Costa, V. B. (2015). Aspectos técnicos e cultivo no Sul do Brasil. Brasília: EMBRAPA.

Dosi, G. (1982). Technological paradigms and technological trajectories: a suggested interpretation of the determinants and directions of technical change. Science Policy Research Unit, 11 (3), 147-162.

Edquist, C. (2006). Systems of Innovation Technologies, Institutions and Organizations. Ottawa: Taylor \& Francis Group.

Emater/rs-Ascar. (2015). Começa a colheita de oliveiras no RS nesta quinta-feira. Disponível em http://www.emater.tche.br/site/noticias/detalhe-noticia. php?id=20864\#.WOWMWYWcHIU.

Freeman, C. (1995). The National System of Innovation in historical perspective. Cambridge Journal of Economics, 19 (1), 15-24.

Gil, A. C. (2011). Métodos e Técnicas de Pesquisa Social. (6. ed.) São Paulo: Atlas. Ibraoliva. (2019). Retrieved from: https://www.ibraoliva.com.br/.

Lee, K., \& Malerba, F. (2017). Catch-up cycles and changes in industrial leadership: Windows of opportunity and responses of firms and countries in the evolution of sectoral systems. Research Policy, 46 (2), 338-351.

Lundvall, B.- A. (1993). National Systems of Innovation. London: Pinter.

Malerba, F. (2002). Sectoral systems of innovation and production. Research Policy, 31 (2), 247-264.

Malerba, F. (2003). Sectoral Systems: How and Why Innovation Differs across Sectors. Em Fagerberg, J., Mowery, D., \& Nelson, R. Handbook of Innovation (pp. 1-21). Milan: Bocconi University.

MAPA (2017). Mapa identifica 45 marcas de azeite fraudados. 2017. Disponível em http://www.agricultura.gov.br/noticias/mapa-identifica-45-marcas-deazeite-fraudados.

Marques, S. (2017). O Guia de Azeites do Brasil 2017. São Paulo: Livrobits.

Mueller, T. (2012). Extravirgindade: o sublime e escandaloso mundo do azeite de oliva. São Paulo: Tapioca.

Negri, F. de, \& Squeff, F de H. S. (2016). Sistemas Setoriais de Inovação e Infraestrutura de Pesquisa no Brasil. Brasília: IPEA.

Olivas do Sul. Galeria: Pomar. (2019). Disponível em http://www.olivasdosul.com. br/galeria/8/pomar.

Oliveira, A. F. de. (2012). Oliveira no Brasil: tecnologias de produção. Belo Horizonte: EPAMIG. 
Paggi, M. S., Konduru, S., \& Yamazaki, F. (2015). A New World Industry Initiative in an Old World Market: The Economics of California Olive Oil Quality Standards. Journal of Food Distribution Research, 46 (1).

Percussi, L. (2011). Azeite: Histórias, Produtores e Receitas. São Paulo: Senac.

Rodrigues, R. M. (2016). A Emergência do Sistema Olivícola no Estado do Rio Grande do Sul. (Dissertação, Tesis da maestria). Disponível em https://www. lume.ufrgs.br/bitstream/handle/10183/149301/001004858.pdf?sequence=1.

Santos, J. F. (2002). El contexto de la olivicultura, la producción y el consumo de aceite de oliva en el mundo. (Dissertação, Tesis de doctorado). Disponível em http://www.tesisenred.net/bitstream/handle/10803/8371/Tjfs04de23. pdf?sequence=4, 295-319.

Schrempf, B., Kaplan, D., \& Schroeder, D. (2013). National, Regional, and Sectoral Systems of Innovation - An overview. European Commission: Community Research and Development Information Service (CORDIS).

SEAPDR/RS. (2018) Nota Técnica: Cadastro Olivícola 2017. Disponível em http:// www.agricultura.rs.gov.br/upload/arquivos/201803/12135955-nota-tecnica-cadastro-olivicola-2017.pdf.

Urieta, D., Menor, A., Caño, S., Barreal, J., Velasco, M. del M., \& Puentes, R. (2018). La Olivicultura Internacional: Difusión histórica, análisis estratégico y visión descriptive. Jaén: Fundación Caja Rural de Jaén.

Wrege, M. S., Steinmetz, S., Júnior, C. R., \& Almeida, I. R. de (2012). Atlas Climático da Região Sul do País: Estados do Paraná, Santa Catarina e Rio Grande do Sul. Distrito Federal: EMBRAPA.

Wrege, M. S., Coutinho, E. F., Pantano, A. P., \& Jorge, R. O. (2015). Distribuição potencial de oliveiras no Brasil e no mundo. Revista Brasileira de Fruticultura, Jaboticabal, 37 (3), 656-666.

Xiong, B., Sumner, D., \& Matthews, W. (2014). A new market for an old food: the U.S. demand for olive oil. Agricultural Economics, 45 (S1), 107-118.

(C) 2020 por los autores; licencia no exclusiva otorgada a la revista Estudios económicos. Este artículo es de acceso abierto y distribuido bajo los términos y condiciones de una licencia Atribución-No Comercial 4.0 Internacional (CC BY-NC 4.0) de Creative Commons. Para ver una copia de esta licencia, visite http://creativecommons.org/licenses/by-nc/4.0 
